\title{
Geo-Politics and the Disaster of the Anthropocene
}

\section{Nigel Clark}

Lancaster Environment Centre, Lancaster University

Lancaster LA1 4YQ

n.clark2@lancaster.ac.uk

\begin{abstract}
In recent years, Earth scientists have begun to talk about, and popularize, the idea of the `Anthropocene’ - a new geologic epoch defined by the emergence of humankind as a geologic agent. Referring, in particular, to the crossing of thresholds or boundaries in Earth systems and the shift into whole new systemic states which no humans have ever experienced, the Anthropocene thesis might be viewed as the positing of a ‘disaster to end all disasters'. As well as looking at some of the motivations behind the Anthropocene concept, this paper explores possible responses to the idea from critical social thought. It is suggested that the Anthropocene and some of the interventionist responses it is already eliciting appear to fit well with a certain kind of `politics of emergency’ in which, critical social thinkers have argued, conditions of crisis or catastrophe are increasingly being used to justify the suspension of established political rights and procedures. However, more positive
\end{abstract}


readings are possible. The paper suggests that the current problematization of global climate tipping points and other `boundary conditions’ might also be taken as indicative of the emergence of a new kind of 'geologic politics'. This novel geopolitics is concerned as much with the temporal dynamics and changes of state in Earth systems as it is with more conventional political concerns revolving around territories and nation state boundaries. It raises questions about the importance not only of political deliberation or negotiation, but of a politics which includes practical, hands-on experimentation with Earth processes. Finally, the idea of the Anthropocene might also be taken as a prompt to consider the very limits of the political, and the challenge of dealing with forces that exceed the effective scope or reach of any polity.

Keywords: disaster, Anthropocene, climate change, Earth systems, politics of emergency, geologic politics. 


\section{Geo-Politics and the Disaster of the Anthropocene}

\section{Introduction: Live fast, die young, leave a good-looking fossil}

In recent years, the question of what residues the human species will leave behind once we are gone has emerged as a theme in academic and popular science (see Weisman, 2007; Zalasiewicz, 2008; Zalasiewicz et al, 2011). Palaeontologist and stratigrapher Jan Zalasiewicz notes that a situation in which discernibly similar fossilized remains are found in many different places across the planet while also being clustered in the same geologic stratum assists researchers in identifying the species in question and placing it in relation to the geologic events that laid down the stratum in which it is found. `Early brilliant success, a worldwide reach, and then a sudden death' is his recipe for a serviceably conspicuous fossilization (2008: 102). Our own species, Zalasiewicz notes, is looking increasingly likely to meet these criteria.

Amongst other more ambiguous or insidious remainders, our urban centres - or what philosopher Michel Serres once described as `enormous and dense tectonic plates of humanity’ (1995: 16) - have a fair chance of leaving a recognisable trace in the stratigraphic record. But only if cities go down quickly. If sea levels rise gradually, buildings and infrastructure will be pummelled into pebbly insignificance by the force of tides and storms. Should sea levels rise rapidly, however, which is likely to be the case if runaway climate change triggers the break-up of the Greenland ice cap, there is 
a fair chance that many coastal cities would rapidly sink beneath the rising ocean, beyond the reach of scouring waves and currents. There, `(o)ur drowned cities ... would begin to be covered by sand, silt, and mud, and take the first steps towards becoming geology. The process of fossilization will begin’ (Zalasiewicz, 2008: 84-5).

An obvious question is, leave a fossil for whom or what to find? At an earlier moment in our modernity, Immanuel Kant considered the possibility that `revolutions of the earth' would one day annihilate human life, as they had done to those long-lost creatures which populate the fossil record (1993: 66-7). Such events, he pondered, would leave the universe bereft of its one and only thinking being. Not only would one of nature's creations vanish, but the very existence of thought would be extinguished for all time, leaving the cosmos cold, barren and unable to reflect upon itself: `all of creation would be a mere wasteland, gratuitous and without final purpose' (Kant, cited in Grant, 2000: 50). Kant’s agonizing was partly prompted by the novel sense of deep geological time that he and fellow $18^{\text {th }}$ century savants were then taking to heart. But it may also have had a more immediate and substantial referent. The destruction of the city of Lisbon by earthquake, fire and tsunami in 1755 had a profound impact on Kant, as it did on many literate Europeans (see Kant, 1994; Chester, 2001). Lisbon, before it became the precursor of a definitively modern form of urban renewal, stood for the exposure of humankind to the forces of the Earth. At the time when faith in an omnipotent and orchestrating deity was waning, Lisbon's fate gestured not only at the vulnerability of one urban centre, but to the frailty of humankind in general in the face of a not-necessarily accommodating cosmos (Ray, 2004; Neiman, 2002). 
Kant's answer to the threat of eventual human extinction was to turn away from the weakness of the flesh and affirm that part of man capable of rising above the blind forcefulness of nature: the human faculty of self-willing and super-sensible reason. This solution is itself now frequently charged with fomenting new problems, not least the back-firing of nature's mastery into environmental upheaval and uncertainty (see Colebrook, 2012: 205). But the problem Kant had the audacity to confront never really went away. From time to time, the convulsions of the Earth continued to play havoc with human achievements great and small. And now, after several centuries of differing priorities and multiple distractions, Kant's greatest fear is back on the agenda.

Today it is the coming of `the Anthropocene' - a term popularised by atmospheric chemist Paul Crutzen in the early 2000s - which most clearly expresses the reinvigorated concern with human species-threatening upheavals of the Earth (see also Weszkalnys, this volume). The concept of the Anthropocene designates a move beyond the geologic conditions characteristic of the 10,000 to 12,000 years since the end of the last glacial epoch- and the shift into a novel epoch whose signature is irreversible human impact on earth and life processes (Crutzen, 2002; Zalasiewicz et al, 2008; Davis, 2008). In 2008, the Stratigraphy Commission of the Geological Society of London passed a motion to consider the possible formalization of the term Anthropocene. An Anthropocene Working Group was set up, tasked with making the decision about the latest contender for a permanent place in the Geological Time Scale (Zalasiewicz et al, 2010: 2228) 
It is anthropogenic climate change, and especially the prospect of passing over thresholds or tipping points in the Earth's climate system that is helping drive forward claims for a geological transition at the planetary scale. Other human impacts, however, such as the triggering of a mass extinction event, the depositing of nuclear and chemical wastes, and the large scale geomorphic transformations of the Earth's surface are also taken into account. In each case, what is under consideration by the commission is not the experience of living through upheavals in Earth systems, but what these changes will mean for the geological stratification of the planet. As sociologist Bronislaw Szerszynski sums up: 'it is important to realise that the truth of the Anthropocene is less about what humanity is doing, than the traces that humanity will leave behind' (2012: 169).

We might imagine the Anthropocene, then, as the disaster to end all disasters. Here I set out at once from disaster studies - the interdisciplinary field which seeks to inform practical measures to help keep people out of the path of hazardous events - and from the thought of the philosopher Maurice Blanchot (1995) for whom the disaster is a crisis of such severity that it undermines our very capacity to make sense of the world. The figure of the Anthropocene announces the prospect of multiple, interconnected and cascading transformations in Earth systems whose current state human beings and other species have come to rely upon. This presents an immense challenge to those tasked with managing environmental change, but at the same time underscores a human embedding in dynamical physical processes which, as Earth scientists would have it, ensures that we `... cannot be in a position to manage the Earth System in any objective fashion' (Steffen et al, 2004: 286). In other words, the Earth sciences disclose material conditions which not only defy prediction, but reveal the precarious 
existence of those beings who are asking questions of it. With the coming of the Anthropocene, literary theorist Timothy Morton argues, geoscience finds itself confronting `an abyss whose reality becomes increasingly uncanny, not less, the more scientific instruments are able to probe it' (2012: 233). And yet, scientists continue to go to the ends of the Earth, literally, in search of evidence about the past, present and future operation of Earth systems.

Such an entanglement of the known and the unknowable, the tryst between that which adds to knowledge and that what radically undoes this knowledge, is not a world away from the paradoxes of the disaster in which Blanchot (1995) immersed himself. For Blanchot and his heirs, the disaster is an event which we cannot simply turn into an object of knowledge - for such is its force and shock that it dismantles the very platforms from which we apprehend reality. And yet, even as the disaster overwhelms our taken for granted senses and sensibilities, it also challenges us to try and begin sensing, thinking, acting in new ways. It ends the world, and begins it turning anew.

Is there more we could do with our renewed sense of implication in `revolutions of the Earth’? What might it mean 'geo-politically’, I ask, to think of the Anthropocene as a disaster - and to think disaster at the spatial and temporal scale of the planet in its entirety? In the light of the failure of all attempts thus far at global governance of climate and other Earth systems - the summit by summit drift of compromise and deferral - what are the political potentialities that might yet be drawn out of the geological conditions of human existence? 
I want to first review the emergence of the concept of the Anthropocene and look at the meaning and implications of the changes assembled under its name. I will then address political risks which have, with some justification, been seen to accompany declarations of a global `state of emergency’, before moving on to consider what else might be done with a dawning sense of geophysical disaster. There is, setting out from this predicament, no clear-cut or obvious passage from the countenance of planetary disaster to a novel sense of geo-politics - the fate of Kant's answer to geologically-induced trauma being an object lesson here. But Kant was right about one thing: the disaster is a moment that calls for an audacious response. If it is not to be a prelude to despair, the disaster must be an incitement to risk-taking, improvisation and experiment. Though none of this should distract us from an understanding that this is also a time for mourning - for dwelling on the experience of loss.

\section{Constructing the Anthropocene}

'The Anthropocene, on current evidence, seems to show global change consistent with the suggestion that an epoch-scale boundary has been crossed within the last two centuries’ observes Zalesiewicz and his colleagues (2011: 840). This shift would take us out of the Holocene, the brief civilization-friendly span of exceptionally clement and stable climate that has reigned on this planet since ever the violent climatic vacillations of the Pleistocene eased off. A more extreme but quite feasible possibility is that the effects of the current human-induced climate change coupled with a major extinction event will bring to a close the 2.5 million plus years of Quaternary period (consisting of the Holocene and the much longer Pleistocene 
epoch) - taking the Earth back to temperatures and sea levels approximating those of mid Pliocene epoch located some three million years ago (see Zalesiewicz et al, 2008: 6).

Speculations about a novel human-induced geological period go back at least as far as Italian geologist Antonio Stoppani's coining of the term the 'Anthropozoic era' in the 1870s, and took a further turn in Russian mineralogist Vladimir Vernadsky’s reflections on the place of humankind in what he referred to as the `biosphere'. Crutzen, 2002: 23; Zalasiewicz et al 2011: 835, Verndasky, 1998, [1 $\left.\left.{ }^{\text {st }} 1926\right]\right)$. If not exactly new, what is remarkable about the recent incarnation of an anthropogenic geologic epoch is its rapid ascendance since Crutzen and marine scientist Eugene Stoermer first introduced the term in 2000 (Crutzen and Stoermer, 2000). Understandably, stratigraphers resist snap decisions: historian Dipesh Chakrabarty noting that it took the International Geological Congress over 50 years to warm to the idea of the Holocene (2008: 209-10). Or as Zalesiewicz and his colleagues remind us: 'The Geological Time Scale is held dear by geologists and it is not amended lightly' (2010: 2228).

If the Anthropocene's elevation from passing remark to a dedicated working group in eight years seems positively fast-track, it is important to keep in mind how dramatically the geosciences have developed over the last six or seven decades. As Kant's musings remind us, a sense that the deep time of the Earth is punctuated by major convulsion has a long history (see Rudwick, 2005). However, it is only since the confirmation of the theory of plate tectonics in the early 1960s that a unified schema has emerged, in which volcanoes, earthquakes and other geologic upheavals 
are viewed as ordinary and ongoing manifestations of the planet's crustal dynamics (Davis, 1996; Clark, 2011: ch1). Intervening decades have seen rapid advances in the understanding of the Earth as a single integrated and dynamical system - through a series of major research projects that have tracked the dynamics of the planet's hydrosphere, atmosphere and lithosphere (the distributions of water, gases and rocks that make up the outermost layers of the Earth), identified the cycles and reservoirs of its main chemical components, and begun to decipher the complex external influences (or 'forcings’) and internal feedback effects that orchestrate periodic shifts in the state of major Earth systems (Westbroek, 1992; Wood, 2004; Davis, 1996).

It is this integrative perspective which provides the basis for understanding the variability of the planet's climate over time and the influence of human activity on the dynamics of climate and other Earth systems. Rather than simply measuring human imprint on the Earth in terms of brute geomorphic transformations - shifting soil and water or the building of substantial structures - it is now possible to gauge anthropogenic impact on Earth systems in terms of changes in the trace components of the atmosphere and other relatively imperceptible chemical and biological signals (see Zalasiewicz et al, 2010: 2229). At the same time, extensive investigation of ice cores and other proxies of past environmental conditions have enabled geoscientists to make confident comparisons between present and previous Earth system states. The resultant evidence of human-induced global climate change, although it is only one of a number of `anthropogenic’ or human-triggered transformations, is generally presented as the key to identifying the onset of the Anthropocene (see Crutzen, 2002). 
While the take-off of fossil-fuelled industrialization is currently the preferred transition point in claims for epochal shift, the pivotal significance of climate change also suggests that we may have yet to witness the Anthropocene’s full unfurling. In particular, it is the as-yet unrealised possibility of passing over a threshold into abrupt and runaway climate change that brings the sobriety of most stratigraphic discourse up against the increasingly alarmist pronouncements of climate science. It is when he is focusing on climate that Crutzen makes clear his view that the more extreme manifestations of the new epoch may lie in the near future. As he observes: `studies ... indicate that global average climate warming during this century may even surpass the highest values in the projected IPCC global warming range of $1.4-5.8{ }^{\circ} \mathrm{C}$ ' (Crutzen, 2006: 211). In the conclusion to one of the first major studies of Earth systems to operationalize the concept of the Anthropocene, climatologist Will Steffen and his colleagues likewise suggest that the most threatening transitions are still to come: `The human-driven changes to the global environment ... may drive the Earth itself into a different state that may be much less hospitable to humans and other forms of life' (Steffen et al, 2004: 299).

Recent evidence points not simply to a failure to stabilize anthropogenic emissions of carbon dioxide, but indicate that $\mathrm{CO} 2$ levels in the atmosphere are actually increasing - at an accelerating rate (Robock et al, 2009: 2, see also Crutzen, 2006: 211-2), with the result that many climate scientists are beginning to view 'dangerous’ - or even ‘extremely dangerous’ - climate change as a serious possibility (see Anderson and Bows, 2011). Journalist Ross Gelbspan reports of his encounters with climate scientists: 'On the record, they use very conservative scientific language; they speak in terms of estimates and trends and probabilities. Off the record, they told me this 
stuff is scary as hell' (2006, unpag). But a growing number of scientists feel obliged to express their full concerns publically. Gaia-theorist James Lovelock, for example, puts it like this: 'Whatever we do is likely to lead to death on a scale that makes all previous wars, famines and disasters small. To continue business as usual will probably kill most of us during the century (2008: 3889).

In this way, what is a 'catastrophic’ in the technical sense of a threshold transition between states or regimes of a physical system (see Scheffer et al, 2001) looks likely to visit the experience of catastrophe or disaster upon social worlds. In response, critical social thinkers characteristically focus on the profoundly uneven distribution of the impacts of climate change and other catastrophes - a predicament rendered still more unconscionable by a consideration of the inverse unevenness of the enjoyment of the benefits of the Earth's material-energetic resources (Roberts and Parks, 2007). However urgent and necessary this approach is, it should not eclipse other possibilities - such as a more speculative `outward' gaze that looks beyond the orbit of humankind to impacts on other-than-human life, and even beyond the terrestrial biosphere itself. Pondering the significance of human-induced mass extinction, Jan Zalasiewicz works on the same grand scale as Kant. Only this time, the human subject is far from centre stage. As Zalasiewicz ruminates:

...conserving living organisms is far more important than conserving fossils (and here one speaks as a life-long palaeontologist). The Earth, in sustaining and harbouring these organisms, is by far the most complex and valuable object in space for many, many billions of miles in any direction. It would 
be not merely be an Earthly disaster if its surface was converted to the kind of wasteland that appeared after the Permian-Triassic or Cretaceous-Tertiary boundary extinction events. It would be a cosmic tragedy, one in which the injuries sustained would not heal for millions of years (2008: 240).

\section{Humanizing Geology?}

The relationship of social, cultural and philosophical thought to the nascent science the Anthropocene is already complicated, and likely to become more so. A decade or so ago, many social scientists would have recognized in the concept an echo - or even a vindication - of their own pronouncements of the `end of nature’ and the rise of an irrecuperably socialised or humanized natural order. Others might still be drawn to the apparent resonance of a sense of human-geologic interactions with notions of hybridity, of co-constitutive culture-natures or cyborg planetary orders. But contemporary critical thinkers are as likely to rail against the apparent recentring of planetary dynamics - however bleakly this is articulated - on the agency of our own species. In the words of literary theorist Tom Cohen, the very idea of the Anthropocene `... seems the epitome of anthropomorphism itself-irradiating with a secret pride invoking comments on our god-like powers and ownership of the planet' (2012: 240).

While there is indeed a discernible whiff of dark grandeur to certain framings of the new geologic epoch, critical engagements of all hues need to be careful not to take the elevation of 'the anthropic' - the role and place of humans - at face value. It is 
important to remember that any ratcheting up of the influence of our own species relative to conventional geological forces plays to our disciplinary interests and political desires at least as much as it does to the affective and empirical dispositions of natural scientists. However ominous it may be, the idea of the Anthropocene - at least at first glimpse - offers many of the same temptations to expand the domain of the collective social agency as any previous depiction of human impact on the environment. This is one way we might read Slavoj Žižek’s claim, which follows on from a spirited engagement with the notion of the Anthropocene:

There is ... something deceptively reassuring in our readiness to assume guilt for the threats to our environment: we like to be guilty since, if we are guilty, then it all depends on us, we pull the strings of the catastrophe, and so in principle we can all save ourselves simply by changing our lives (2011: 423).

But even Žižek - following Dipesh Chakrabarty’s (2008) path-breaking engagement with the idea of human geologic agency - seems to see the Anthropocene predominantly in terms of what it says about our species. What is vital for critical thinkers in the humanities and social sciences to recognise, however, is that the scientific thematization of the Anthropocene is as much about the decentring of humankind as it is about our rising geological significance. At the heart of the developments in Earth sciences in the latter $20^{\text {th }}$ and early $21^{\text {st }}$ centuries is the keen sense that Earth systems are inherently changeable, with or without human influence. As Steffen and his colleagues sum up: 'detailed paleo-records show that the Earth is never static and it is almost impossible to define an equilibrium state; variability 
abounds at nearly all spatial and temporal scales' (Steffen et al, 2004: 295). It is this intrinsic variability which explains why climate and other Earth systems are susceptible to human impacts or `forcings’. As climatologist Richard Alley explains, in relation to global climate: 'Sometimes a small push has caused the climate to change a little, but other times, a small push has knocked Earth's climate system into a different mode of operation’ (2000: 13; see also Broecker, 1987).

The trouble is that, even after all the interrogations of the nature-culture binary of recent decades, researchers in the social science and humanities still tend to treat natural and social agency as sliding points on a linear scale, analogous to a tug of war in which one side gains as the other loses. Similar imagery does arise in the natural sciences, but in general the relatively novel acknowledgement of humans as a `global forcing agent' does not seems to imply any corresponding diminution of the universe's more established forces (see Zalasiewicz et al, 2010: 2228). A humantriggered mass extinction event might well be considered a tragedy of cosmological proportions, but as Zalasiewicz's musings suggest, a catastrophe of this magnitude ought to be viewed in the context of a series of similarly momentous `boundary events' which have had nothing remotely to do with humans. Through its own dynamics and interactions with the solar system, the Earth is quite capable of generating upheavals, geoscientists remind us, which is precisely why it is possible to identify a sequence of transitions in the Geological Time Scale.

There is ample evidence indicating that the idea of a transition from the Holocene to the Anthropocene is implicated in the deepening ethical-political entanglements of scientific research that are associated with the era of global environmental change (see 
Frodeman, 2000: vii - x). Already the concept of the Anthropocene has been marshalled to make a case for identifying a range of `planetary boundaries’ that designate `the safe operating space for humanity’ (Rockstrom et al, 2009). This is a move - controversial in some quarters - with clear policy implications. As Zalasiewicz et al note, in relation to this operationalization of the Anthropocene concept in the framing of planetary boundaries: 'formalization may represent “official” acknowledgment that the world has changed, substantially and irreversibly, through human activity - an acknowledgment akin to the IPCC consensus statements on climate change' (2010: 2230). They go on to gesture at the wider political ramifications, including the risks, of foregrounding human geological agency:

The concept of the Anthropocene might ...become exploited, to a variety of ends. Some of these may be beneficial, some less so. The Anthropocene might be used as encouragement to slow carbon emissions and biodiversity loss, for instance; perhaps as evidence in legislation on conservation measures; or, in the assessment of compensation claims for environmental damage. It has the capacity to become the most politicized unit, by far, of the Geological Time Scales and therefore to take formal geological classification into uncharted waters (Zalasiewicz et al 2010: 2231).

While Zalasiewicz and his colleagues fall short of suggesting that the proclamation of the Anthropocene epoch is primarily politically or ethically motivated, this is clearly science which has come some distance from principles of disinterestedness or 
affective neutrality. This in turn raises interesting questions for the political and the ontological commitments of critical social and humanistic thought (see Mackenzie and Murphie, 2008; Clark, 2011: xix-xx). Perhaps, rather than excoriating physical scientists for conjuring up concepts which bolster their 'god-like powers’, we might deign to see the idea of the Anthropocene as an overture towards the world of social thought and action: something in the nature of a rift-bridging offering or gift.

In an influential formulation, sociologist of science Bruno Latour (1993) has argued that the `modern constitution’ has involved parallel manoeuvres in which the natural sciences have evacuated the presence of human agency and ordering from the realities they describe while social thinkers have ignored the manifold non-humans which help compose the social (see Farias, this volume). If there is any substance to this claim, then the rapid uptake of the idea of humans as a global geologic agent represents a significant transformation in the operation of the natural sciences - a shift that raises questions about what might figure as a corresponding gesture on the part of the social sciences or humanities. Not an exchange, perhaps, but a counter-gift, with something of the excess or exorbitance which sets the gift apart from an `economic’ transaction.

It is not nearly enough, I would argue, that social or cultural thinkers simply take hold of the idea of a fully humanized geology and use it to extend our own disciplinary dominions. Or even chose the predictable and non-excessive option of meeting in a middle ground. What we need to attend to are the ways that the very issue of geological boundary-transition which underpins the figuring of the Anthropocene put social thought into contact with other epochs and eras. 
While a case might be made that natural scientists ought to take the `stratifications` or hierarchies proper to human society more seriously, the onus is also on us consider other geological strata, other planetary upheavals, than those in which humankind is now implicated. Whereas much recent social theoretical work around questions of society-nature relations assumes some kind of symmetry between social and natural processes (see Clark, 2011: Ch 2), one of the most profound (if initially counterintuitive) effects of Anthropocene discourse is to disclose the radical asymmetry of human and nonhuman forces. By encouraging us to imagine worlds both before and after us, Anthropocene studies offer a bold depiction of an Earth that has no need of humankind, a planet which will one day quite rapidly - in geological terms - scour most of the traces of human existence from its surface. At the same time, we are reminded of the extent to which all human life remains utterly dependent on geologic and biological conditions bequeathed to us by Earth and cosmic systems. And indeed, reliant on certain states or regimes of Earth systems which in many cases represent only a narrow range of their potential operating spaces.

A generous - and apposite - response to discourses of the Anthropocene, then, might be a new willingness in critical social, cultural and philosophical thought to embrace the fully inhuman, in all its variability and volatility. This means putting thought and questions of practical action into sustained contact with times and spaces that radically exceed any conceivable human presence - with all the risks and the paradoxes this entails. It would require us to connect up the question of political possibility with the dynamics and the intransigence of vast domains which are themselves recalcitrant to the purchase of politics. In this way, the Anthropocene viewed in all its disastrousness - confronts `the political’ with forces and events that 
have the capacity to undo the political, along with every other human achievement, by removing the very grounds on which we might convene and strategise - to the extent of annihilating political beings themselves. It puts politics - the realm of what we can and might do differently - head to head with what philosopher Claire Colebrook refers to as the `monstrously impolitic’ (2011: 11, see also 2012; Clark, 2012). Or to put it another way, it dramatically raises the stakes on the familiar question of `how to find freedom in relation to a past we are stuck with and did not author' (Honig, 2009: 28).

\section{Planetary Crisis and the Politics of Emergency}

But is this a good time to evoke realities that exceed the political? Is it wise to be pumping up `the impolitic’ at a juncture where the threat or the visitation of disaster seems to have become a justification for rolling back the achievements of political struggle? One of the most commanding themes in contemporary political thought popular and academic - is the idea that states of emergency are being wielded by powerful actors to advance their own interests at the expense of less-resourced and more vulnerable groups (see Honig, 2009: 87; Clark, 2013). Disastrous events or threats of impending disaster, it is argued, are being presented as the rationale for stringent and far-reaching regulatory practices that have profoundly `antipolitical’ connotations. This mode of critique, I want to suggest, offers a well-tuned framework for addressing some of the key proposals for responding to the upheavals of a humanized geology, even before the idea of Anthropocene has been fully absorbed into critical social and political thought. 
In a world in which it is widely accepted that significant hazards and risks accompany intensifying globalization - a mood exacerbated by the events of 9/11 - it has been noted that authorities at every scale are taking it upon themselves to render the spaces under their jurisdiction more `secure’. Along with rogue human collectivities, physicmaterial agencies such as biological life or climatic processes are also being addressed as elements with the potential to act unpredictably at a global level - and thus to threaten the security of cities, regions or nation states (Dillon, 2007; Cooper, 2006). What concerns critical commentators is not so much the acknowledgement of these risks, as the way they are being mobilized to make it appear as though securitization measures are the only viable response (Braun 2007: 15). Drawing variously on the work of Walter Benjamin, Carl Schmitt, Michel Foucault, and especially Giorgio Agamben, progressive thinkers have sought to expose the ways in which the exceptional conditions of the emergency or disaster are being invoked with such frequency that they risk being normalized (Aradau and van Munster, 2011: 111). A generalized condition where potentially catastrophic events might suddenly irrupt in any form, at any moment, anywhere in the world, they argue, is being invoked to justify sweeping new measures of surveillance, ordering and regulation, to the point of undoing hard won political freedoms. But perhaps most relevant to the event horizon of the Anthropocene, is the claim that active pre-emption - getting in first and the changing the conditions which might precipitate a crisis - is a vital tactic of forces of securitization (see Dillon, 2007).

‘Pre-emption’, observes sociologist Melinda Cooper, ‘transforms our generalized alertness into a real mobilizing force, compelling us to become the uncertain future 
we're most in thrall to' (2006: 125). The trouble with pre-emptive measures, she cautions, is that they can be just as unpredictable and irruptive as the hazards they would defuse (2010: 184). It is precisely this logic that Cooper recognises in a 2003 report on the consequences of abrupt climate change for the US which proposes 'geoengineering' the Earth’s climate to stave off dangerous climate change:

The paradox of this argument is that it calls for a strategic intervention into the atmosphere in order to pre-empt the worst effects of climate change, while acknowledging that such an intervention may itself be indistinguishable from the process of climate change - that is to say, equally unpredictable, incalculable and turbulent in its unfolding (2010: 184).

Over the last decade or so, the possibility of technological intervention into Earth systems on a planetary scale has been on the ascendant in some scientific communities as an emergency measure which might be attempted if global climate looks likely to pass into a ‘dangerous’ or ‘extremely dangerous’ phase. Several key thinkers associated with the Anthropocene idea, including Paul Crutzen, have speculated that some form of intentional large-scale climate modification - or 'geoengineering' - might be considered, in the light of the failure of global climate governance to reverse or even slow greenhouse gas emissions (Crutzen, 2006: 214). Nearly all proponents of geoengineering research, however, stipulate that this would be an emergency measure, just as they stress that collective political action to abate greenhouse gas emission would be greatly preferable to technical interventions to alleviate or counterbalance the effects of changing atmospheric composition. 
For Cooper, the possibility of a geotechnological pre-empting of dangerous climate change not only comes with profound risks and uncertainties: the mindset of a permanent state of emergency to which it belongs shores up existing imperial power - the power of global or planetary capitalism - at the expense of alternative, more progressive possibilities (2010: 184). If not quite in these terms, many other commentators, including a number who are involved in research in the geoengineering field, have voiced strong concerns about a commitment to technical fixes taking on a life of its own at the expense of pursuing socio-political transformation (Hamilton, 2011; Keith, 2000; cf Heartland Institute, 2007).

As it becomes clearer that is not simply climate, but a range of interconnected Earth systems that are currently under profound stress (see Steffen 2006), geotechnical responses are taking into their purview more than just climate stabilisation. ${ }^{1}$ Geoengineering, in this sense, might best be viewed as a response to all the entangled and mutually reinforcing geologic transformations which gather under the rubric of the Anthropocene. Debates about geoengineering, in other words, could be seen as a nascent expression of the much bigger issue of governing the Anthropocene - as a vehicle by which the question of the political implications of the experience of wholesale planetary emergency is being broached.

Whether or not `apocalyptic’ imagery serves to promote or incapacitate politicization has long been debated in environmentalist circles and in critical social thought (see Swyngedouw, 2007; cf Yusoff and Gabrys, 2011). In another register and another field, the question of whether `actual' disasters provide opportunities for political 
transformation, or whether they are primarily occasions for the entrenchment of preexisting power relations, has also been a matter of lively discussion (Cuny, 1983; Pelling and Dill, 2010, Kelman, 2012, Tironi, this volume ). Whereas Naomi Klein’s (2008) bestselling inquiry into the machinations of `disaster capitalism’ comes down firmly on the side of the latter, geographer Mark Pelling and anthropologist Kathleen Dill sift through a range of case studies to arrive, cautiously, at a more hopeful prognosis. ‘Disaster shocks’, they propose `open political space for the contestation or concentration of political power and the underlying distributions of rights between citizens and citizens and the state' (2010: 34).

Engaging in a more general sense with the political potential of the crisis or emergency, political theorist Bonnie Honig comes to a similar conclusion. Taking issue with the rush of recent critical work that characteristically equates the state of emergency with the suspension of civil liberties and the closure of political possibility, Honig argues for the fundamental ambivalence of invoking emergency, observing that no declaration of emergency can dictate how it will be received, interpreted and acted upon. By contrast to claims that the `emergency brings an end to real politics', she seeks out and discovers new possibilities for political renewal and change: `hidden resources and alternative angles of vision that might motivate action in concert in emergency settings' (2009: xv; see also Aradau and van Munster, 2011: 11)

But what might these political possibilities be? What is demanded of the political in the face of the threats and challenges designated by the Anthropocene? In the final section, I want to sketch out some of the ways that responses to the current geologic 
predicament of humankind are awakening to Michel Serres’ call for a ‘geopolitics in the sense of the real Earth’ (1995: 44; see also Dalby, 2007). More than a matter of confronting the consequences of our own actions, I want to suggest, a growing sense of inherent instability of the Earth are beginning to impact upon our understanding of the composition of the political; our sense of what it is we work with - or against when we mobilize collectively.

\section{Toward an Anthropocene Geopolitics}

Resonating with other researchers in the field of science and technology studies, Sheila Jasanoff writes of `the indeterminacy and complexity of many novel risks, and their refusal to stay within neatly drawn geopolitical lines’ (2010: 19; see also Petersen, this volume). It is timely, however, to ask what exactly the `geo’ in 'geopolitical' is doing in this scenario, and what claims about the coming of an Anthropocene epoch might mean for such an understanding of 'geopolitical lines’. Perhaps the most crucial lesson of the Anthropocene is that the Earth itself must be understood as much more than a mere surface or stage on which political contests take place: it must acquire a volumetric or vertical dimension (Dalby, 2013; see also Elden 2013). That is to say, the 'geopolitical' can no longer simply refer to a horizontal and synchronous globality.

But this requires something more than extending the conventional concerns of geopolitical discourse and practice upwards into the atmosphere or downwards into the depths of the ocean or Earth. It requires us to bring politics into an intensive engagement with the planet's own dynamics: its processes of sedimentation and mobilization, its layering and folding, its periodicities and singularities. This means 
that the crucial borders or thresholds on the political agenda are not only those which divide nations or other socially-inscribed territorial divisions of the Earth's surface, but also the spatio-temporal junctures at which one state or regime of an Earth system passes into another (Clark, 2011: Ch 8, on the Cenomanian Turonian extinction or boundary event, see Wezkalnys, this volume). Or to put it another way, politics must expand its concerns with the shaping and reshaping of territory to embrace processes of stratification and destratification (see Deleuze and Guattari: 1987: 40 -74).

When it comes to the threat of crossing boundaries or thresholds in Earth systems, as Johan Rockström and his interdisciplinary team observes: `(c)urrent governance and management paradigms are often oblivious to or lack a mandate to act upon these planetary risks' (2009: unpag). While the repeated failure of climate summits to achieve the binding commitments necessary to ward off ‘dangerous’ or `extremely dangerous' climate change is the most conspicuous manifestation of this shortfall, the relative paucity of attention to other imminent or already transgressed `planetary boundaries’ is no less revealing (Anderson and Bowes, 2011; Rockström et al, 2009). Recent calls for what has been variously termed `planetary stewardship’ (Steffen et al, 2011); `Earth System governmentality’ (Lövbrand et al, 2009); and `global earth system governance’ (Dryzek and Stevenson, 2011: 1873) express a growing recognition of the need for new or greatly strengthened frameworks to meet the political challenge of maintaining Earth systems in socially desirable states.

Needless to say, normative reasoning is far from enough to conjure such architectures into existence. Any conceivable success, political theorists John Dryzek and Hayley Stevenson remind us, must work through and from existing experience (2011: 1873). 
But what kinds of experience might be relevant here? We have seen that critical social thinkers can be as apprehensive about the successful operationalizing of strategies to ‘manage’ Earth systems as they are about inadequate planetary governance. While radical critics tend to champion a generalized advancement of democratic or deliberative political processes, they are often less than forthcoming about their own preferences for responding practically to the challenges posed by dynamic Earth or life processes. There are, of course, no easy answers to the question of how to gain experience of 'governing' the forces of the Earth. As Latour argues, novel situations configured by messy admixtures of social and material ingredients present a new imperative to improvise or experiment (see Farias, this volume). When it comes to situations with the scale and complexity of global climate change, however, he suggests we are way out of our depth: 'The problem is that while we know how to conduct a scientific experiment in the narrow confines of a laboratory, we have no idea how to pursue collective experiments in the confusing atmosphere of a whole culture' (2003: 31).

But who exactly the 'we' is in this statement raises questions of its own - inviting us to consider the historical and geographical depth of the human experience of living through environmental extremes. One of the motivations for thinking through geological durations, after all, is to contextualise the events of the present in a much broader framework. As philosopher-geologist Robert Frodeman explains, (e)arthquakes, floods, hurricanes, and droughts are places where deep time erupts into more familiar temporal rhythms' (2003: 125). If such threshold transitions or destratifications might be seen as ways in which the Earth experiments with its human (and nonhuman) inhabitants, they are equally occasions which oblige human 
populations to respond with experiments of their own. Many of those peoples who still live in relatively close proximity to the rhythms and upheavals of the Earth have learned how best to shelter from extreme events, when to move to safer ground, how to channel excess energies, what to cache or stockpile, and when to fight fire with fire (Clark, 2008; 2011). The shaping of such practices and the decisions out of which they are forged might well be seen as a form of geologic politics - though this is not necessarily `politics’ which is played out in the patient, deliberative manner social theorists such as Latour or Ulrich Beck (1995) would prefer (see Michael, this volume).

As philosophers Gilles Deleuze and Felix Guattari (1987) suggest, our engagement with the organizational layerings and dynamics of our material worlds can be more than reactive or defensive. There is always the possibility of constructive traversals of compositional strata, of intercession in the flows of matter and energy, with no purpose other than the joy of experimentation and the pleasure of creating new forms and structures. At the same time, Deleuze and Guattari counsel about the dangers of `a too-sudden destratification’, warning that this ‘will sometimes end in chaos, the void and destruction, and sometimes lock us back into the strata' (1987: 503). If this cautionary note applies in a general sense to the planetary predicament that results from unrestricted consumption of fossil fuels, so too is at apposite with regard to strategies for deliberate geotechnical interventions into Earth systems - not least the unauthorised geoengineering experiment that recently took place off the Canadian coast (Geere, 2012). 
While geoengineering proposals have justifiably attracted critical scrutiny, they have in the process helped put practical experimentation with dynamic Earth processes more explicitly on the academic and the political agenda (see Galarraga and Szerszynski, 2012). Today, alongside speculative planet-scaled `smoke and mirrors’ geoengineering schemes (Humphreys, 2011), a host of more moderately scaled and easily reversible strategies for intervening in Earth systems are currently under experiment and review. These include localized alterations of the planet's albedo involving brightening of water and transformations of vegetative cover or the built environment, a range of forms of biological and geological carbon capture such as soil enhancement using charred organic matter, and a whole raft of proposals to protect and enhance ecosystems (Olson, 2012; see also Chris, 2013). Such strategies are of interest not because they promise quick solutions to climate change and other Earth system threshold problems, but because they give an idea of the possible mix of techno-physical and socio-political issues that may characterize emergent `geopolitical' agendas. They direct our attention not only to the kind of material interventions over which collective decisions must be made, but to the need for political constituencies to consider their own everyday practical or material implication in the dynamics of Earth systems - to ask how they themselves might take matter-energy flows into their own hands. And this implies that, just as critical social thinkers increasingly demand political awareness on the part of Earth systems scientists and engineers, so too must we require of ourselves a willingness to commit to some form of experimental intervention in Earth processes - with all the risks this inevitably entails. 
Arguably the most audacious proposal on the contemporary geo-political agenda one that also seeks to legitimate itself through a rhetoric of planetary emergency - is to leave fossil fuels in the ground (see Temper et al, 2013). If industrialism - or more precisely, industrial capitalism - has established itself as a geologic force primarily through growing reliance on fossilised hydrocarbons, then the imposition of any significant restriction on fossil fuel extraction and usage would itself constitute an experimental geologic intervention. It would be at once a mode of geotechnics and an object of geo-politics. But any mass reduction of reliance upon oil, gas and coal would also withdraw the primary means by which a large proportion of the planet's human population currently modulates many of the effects of the variability of the Earth systems - both directly and indirectly. To decrease reliance on the buried solar energy of past geologic eras, in other words, is not simply to turn to a more benign and dispersed solar through-flow. It is to renew, after a geologically infinitesimal interval, our characteristic exposure to the volatile forces of the Earth and the cosmos.

Not that human susceptibility to dynamic physical processes ever really withdrew, as the incessant and escalating impact of natural disasters on human populations makes plain. What the emergent geo-politics of the Anthropocene is beginning to look like, I have been suggesting, is a complex blend of socio-political and physico-material negotiations, in which each side of the confluence is as experimental or improvisational as the other. As is the message of disasters in general, and the ascending mega-disaster of the Anthropocene in particular, this is more or other than a matter of expanding the realm of effective political-material deliberation until it becomes coextensive with nature or the Earth. It is about fronting up to the inescapable - though shifting and non-objectifiable - limits of the political; about 
recognising the crucial importance of the juncture where the effective range of collective intervention comes up against the `monstrously impolitic’ reaches of the Earth and cosmos.

Acknowledging that material existence vastly exceeds the measure of the human - an undercurrent of the Anthropocene idea - drives home the fact that all interventions in Earth systems are matters of trial and error. At whatever scale they are attempted, experiments with flows of matter and energy have a fair chance of failing, falling short, or having unintended consequences. Efforts to deflect or modulate disaster, in this sense, can be expected to precipitate new disasters. The geo-political or cosmopolitical challenge of the Anthropocene then, may be as much about how we chose to engage with others whose experiments have fallen short or been overwhelmed, as it is about how we make decisions about our own strategic interventions. And ethical relating too, as the most searching theorists of the disaster have long observed, is a matter of risky experimentation and urgent improvisation.

\section{References}

Alley, R. B., (2000), The Two-Mile Time Machine: Ice Cores, Abrupt Climate

Change, and Our Future. Princeton: Princeton University Press. 
Anderson, K. and Bows, A., (2011), ‘Beyond `dangerous’ climate change: emission scenarios for a new world', Philosophical Transactions of the Royal Society A 369: 20 $-44$.

Aradau, C and van Munster, R., (2011), Politics of Catastrophe: Genealogies of the Unknown, London: Routledge.

Beck, U., (1995), Ecological Politics in an Age of Risk. Cambridge: Polity Press.

Blanchot, M., (1995), The Writing of the Disaster. University of Nebraska Press. Lincoln and London.

Braun, B., (2007), `Biopolitics and the Molecularization of Life’, Cultural Geographies 14: 6-28.

Broecker, W. S., (1987), 'Unpleasant Surprises in the Greenhouse', Nature 328 (9 July) 123-6.

Chakrabarty, D., (2008), The Climate of History: Four Theses, Critical Inquiry 35: $197-222$.

Chester, D., (2001), 'The 1755 Lisbon Earthquake’, Progress in Physical Geography 25 (3) 363-383. 
Chris, R., (2013), Geoengineering, climate change and future generations: the emergence of systems thinking in response to complexity and uncertainty, $\mathrm{PhD}$ Thesis, Department of Geography, The Open University, Milton Keynes.

Clark, N., (2008), ‘Aboriginal Cosmopolitanism’, International Journal of Urban and Regional Studies. 32(3), 737-744.

Clark, N., (2010), 'Volatile Worlds, Vulnerable Bodies: Confronting Abrupt Climate Change', Theory, Culture \& Society, 27 (2-3):

Clark, N., (2011), Inhuman Nature: Sociable Life on a Dynamic Planet, London: Sage.

Clark, N., (2012), ‘Rock, life, fire: speculative geophysics and the Anthropocene’, Oxford Literary Review 34. 2: 259-276.

Clark, N., (2013), ‘Mobile life: biosecurity practices and insect globalization’, Science as Culture, 22 (1) 16-37.

Cohen, T., (2012), ‘Polemos: 'I am at war with myself’ or, Deconstruction $^{\mathrm{TM}}$ in the Anthropocene?' The Oxford Literary Review 34.2 : 239-257

Colebrook, C., (2011), “Matter without bodies”, Derrida Today 4 1-20

Colebrook, C., (2012), 'Not Symbiosis, Not Now: Why Anthropogenic Change 
Is Not Really Human’ The Oxford Literary Review 34.2: 185-209

Cooper, M., (2006), 'Pre-empting Emergence: The Biological Turn in the War on Terror', Theory Culture \& Society 23 (4) 113-135.

Cooper, M., (2010), 'Turbulent worlds: financial markets and environmental crisis', Theory, Culture \& Society 27 167-190

Crutzen, P. J. and Stoermer, E. F., (2000), 'The “Anthropocene” ', IGBP Newsletter 41: $17-18$.

Crutzen, P. J., (2002), 'Geology of Mankind’, Nature 415 (6867) 3: 23.

Crutzen, P. J., (2006), `Albedo Enhancement by Stratospheric Sulphur Injections: A Contribution to resolve a Policy Dilemma?' Climatic Change (2006) 77: 211-219

Cuny, F., (1983), Disasters and development. Oxford: Oxford University Press.

Dalby, S., (2007), “ Anthropocene geopolitics: globalisation, empire, environment and critique”, Geography Compass 1 103-118

Dalby, S., (2013), 'The Geopolitics of Climate Change’, Political Geography, in press

Davis, M., (1996), `Cosmic Dancers on History's Stage? The Permanent Revolution in the Earth Sciences', New Left Review 217: 48-84. 
Davis, M., (2008), 'Living on the Ice Shelf: Humanity's Meltdown,'

TomDispatch.com June 26. Available at: http://www.tomdispatch.com/post/174949 (accessed 20/11/2009).

Deleuze, G. and Guattari, F., (1987), A Thousand Plateaus: Capitalism and Schizophrenia. Minneapolis: University of Minnesota Press.

Dillon, M., (2007), `Governing Terror: The State of Emergency of Biopolitical Emergence’, International Political Sociology 1, 7-28.

Dryzek, J and Stevenson, H., (2011), `Global Democracy and Earth System Governance’, Ecological Economics, 70: 1865 - 1874.

Elden, S., (2013), Secure the Volume: Vertical Geopolitics and the Depth of Power, Political Geography, 34, 35-51.

Frodeman, R., (2000), `Preface: Shifting Plates: The New Earth Sciences’, in Frodeman, R (ed) Earth Matters: The Earth Sciences, Philosophy, and the Clams of Community. Upper Saddle River, NJ: Prentice-Hall.

Frodeman, R., (2003), Geo-logic: Breaking Ground between Philosophy and the Earth Sciences, Albany NY: University of New York Press.

Galarraga. M. and Szerszynski, B., (2012), 'Making Climates: Solar Radiation 
Management and the Ethics of Fabrication', in Preston C (ed.) Engineering the

Climate: The Ethics of Solar RadiationManagement , Lexington, MA,

Gelbspan, R., (2006), `Scepticism, Disinformation and Obstruction in U.S Climate

Circles’, Tipping Point Conference, Environmental Change Institute, Oxford

University, http://www.capefarewell.com/climate-science/comment-

opinion/scepticism.html (accessed 16 March 2013)

Grant, I., (2000), `Kant after Geophilosophy: The Physics of Analogy and the

Metaphysics of Nature', in A. Rehberg and R. Jones (eds) The Matter of Critique:

Readings in Kant's Philosophy: Manchester: Clinamen Press.

Heartland Institute., (2007), 'Geo-engineering seen as a practical, cost-effective global warming Strategy', Heartlander http://news.heartland.org/newspaperarticle/2007/12/01/geo-engineering-seen-practical-cost-effective-global-warmingstrategy

Geere, D., ( 2012), `Rogue geoengineer creates massive Pacific plankton bloom’, Wired http://www.wired.co.uk/news/archive/2012-10/20/plankton-bloom

Hamilton, C., (2011), `Ethical anxieties about geoengineering: moral hazard, slippery slope and playing God’, http://www.clivehamilton.net.au/cms/media/ethical_anxieties_about_geoengineering. pdf (accessed 16 March 2013) 
Honig, B.,(2009), Emergency Politics: Paradox, Law, Democracy, Princeton: Princeton University Press.

Humphreys, D., ( 2011), `Smoke and mirrors: some reflections on the science and politics of geoengineering' Journal of Environment \& Development 20 99-120

Jasanoff, S., (2010), `Beyond Calculation: A Democratic Response to Risk, in A Lakoff (ed) Disaster and the Politics of Intervention, New York: Columbia University Press.

Kant, I., (1993, $1^{\text {st }}$ 1938), Opus Postumum. Cambridge: Cambridge University Press.

Keith, D., (2000), 'Geoengineering the climate: history and prospect', Annual Review of Energy and the Environment 25: 245-84

Kelman, I., (2012) ,Disaster Diplomacy: How Disasters Affect Peace and Conflict. Routlege, Abingdon.

Klein, N., (2008), The Shock Doctrine: The Rise of Disaster Capitalism. London: Penguin.

Latour, B., (1993), We Have Never Been Modern. Cambridge, MA.: Harvard University Press. 
Latour, B., (2003), `Atmosphère, Atmosphère’, in S. May (ed) Olafur Eliasson: The Weather Project. London: Tate Publishing.

Lövbrand, E., Stripple, J. and Wiman, B.,(2009), `Earth System governmentality:

Reflections on science in the Anthropocene', Global Environmental Change, 19: 7-

13.

Lovelock, J., (2008), ‘A geophysiologist's thoughts on geoengineering’, Philosophical Transactions of the Royal Society A 366: 3883-3890.

Mackenzie, A. and Murphie, A., (2008), `The Two Cultures Become Multiple?

Sciences, Humanities and Everyday Experimentation', Australian Feminist Studies, 23 (55): 87-100.

Morton, T., (2012), ‘Ecology without the Present', The Oxford Literary Review 34.2 : 229-238.

Neiman, S., (2002), Evil in Modern Thought: An Alternative History of Philosophy. Princeton, NJ.: Princeton University Press.

Olson, R., (2012), `Soft Geoengineering: A Gentler Approach to Addressing Climate Change’, Environment: Science and Policy for Sustainable Development, 54 (5): 29 39. 
Palsson, G., Szerszynski, B., Sorlin, S., Marks, J., Avril, B., Crumley, C., Hackmann, H., Holm, P., Ingram, J., Kirman, A., Pardo Buendía, M. and Weehuizen. R., (2012), 'Reconceptualizing the ‘Anthropos’ in the Anthropocene: Integrating the social sciences and humanities in global environmental change research’ Environmental Science and Policy http://dx.doi.org/10.1016/j.envsci.2012.11.004 (accessed 16 March, 2013)

Pelling, M. and Dill, K., (2010), `Disaster politics: tipping points for change in the adaptation of sociopolitical regimes’ Progress in Human Geography 34(1): 21-37

Ray, G., (2004), `Reading the Lisbon Earthquake: Adorno, Lyotard, and the Contemporary Sublime’, Yale Journal of Criticism, 17 (1) 1-18.

Robock, A., Marquardt, A., Kravitz, B., and Stenchikov, G., (2009), 'Benefits, risks, and costs of stratospheric geoengineering', Geophysical Research Letters 36: 1-9

Roberts, J. T. and Parks, B. C., (2007), A Climate of Injustice: Global Inequality, North-South Politics, and Climate Policy, Cambridge, MA.: MIT Press.

Rockström, J., Steffen, W., Noone, K., Persson, Å., Chapin, F., Lambin, E., Lenton, T., Scheffer, M., Folke, C., Schellnhuber, H., Nykvist, B., De Wit, C., Hughes, T., van der Leeuw, S., Rodhe, H., Sörlin, S., Snyder, P., Costanza, R., Svedin, U., Falkenmark, M., Karlberg, L., Corell, R., Fabry, V., Hansen, J., Walker, B., Liverman, D., Richardson, K., Crutzen, P., and Foley, J., (2009), `Planetary boundaries: exploring the safe operating space for humanity. Ecology and 
Society 14(2): 32. http://www.ecologyandsociety.org/vol14/iss2/art32/ (accessed 16 March 2013).

Rudwick, M., (2005), Bursting the Limits of Time: The Reconstruction of Geohistory in the Age of Revolution. Chicago: University of Chicago Press.

Serres, M., (1995), The Natural Contract, Ann Arbor: University Of Michigan Press.

Swyngedouw, E., (2007), ‘Impossible ‘Sustainability’ and the Post-Political Condition', in R. Krueger and D. Gibbs (eds), The Sustainable Development Paradox, (New York: Guilford Press, New York) 13-40.

Steffen, W., Sanderson, A., Tyson, P., Jäger, J., Matson, P., Moore, B., III, Oldfield, F., Richardson, K., Schellnhuber, H., Turner, B., Wasson, R., (2004), Global Change and the Earth System: A Planet Under Pressure , Berlin: Springer-Verlag

Steffen, W., Persson, A., Deutsch, L., Zalasiewicz, J., Williams, M., Richardson, K., Crumley, C., Crutzen, P., Folke, C., Gordon, L., Molina, M., Ramanathan, V., Rockström, J., Scheffer, M., Schellnhuber, H.J., and Svedin, U., (2011), `The Anthropocene: From Global Change to Planetary Stewardship’, Ambio 40(7): 739-61.

Szerszynski, B (2012), ` The End of the End of Nature: The Anthropocene and the Fate of the Human’ The Oxford Literary Review 34.2: 165-184

Temper, L., Yánez, I., Sharife, K., Ojo, G., Martinez-Alier, J., Combes, M., 
Cornelissen, K., Lerkelund, H.,Louw, M., Martínez, E., Minnaar, J., Molina, P., Murcia, D., Oriola, T., Osuoka, A., Pérez, M. M., Roa Avendaño, T.,Urkidi, L., Valdés, M., Wadzah, N., Wykes, S., (2013), Towards a Post-Oil Civilization: Yasunization and other initiatives to leave fossil fuels in the soil. EJOLT Report No. 6.

Vernadsky, V., (1998, $1^{\text {st }}$ 1926),The Biosphere. New York: Copernicus.

Westbroek, P., (1992), Life as a Geological Force: Dynamics of the Earth. New York: W. W. Norton.

Weisman , A., (2007), The World without Us, New York: Virgin. , Wood, D., (2004), Five Billion Years of Global Change: A History of the Land. New York: The Guilford Press.

Yusoff, K. and Gabrys, J., (2011), “Climate change and the imagination”, WIREs Climate Change $2 \quad 516-534$

Zalasiewicz, J., (2008), The Earth After Us, Oxford: Oxford University Press.

Zalasiewicz, J., Williams, M., Steffen, W., and Crutzen, P., (2010), 'The New World of the Anthropocene', Environmental Science and Technology 44: 2228 - 2231. 
Zalasiewicz, J., Williams, M., Smith, A., Barry, T., Coe, A., Bown, P., Brenchley, P., Cantrill, D., Gale, A., Gibbard, P., Gregory, F., Hounslow, M., Kerr, A., Pearson, P., Knox, R., Powell, J., Waters, C., Marshall, J., Oates, M., Rawson, P., and Stone, P., (2008), 'Are we now living in the Anthropocene?’ GSA Today 18:4-8.

Zalasiewicz, J., Williams, M., Fortey, R., Smith, A., Barry, T., Coe, A., Bown, P. Rawson, P., Gale, A., Gibbard, P., Gregory, J., Hounslow, M., Kerr, A., Pearson, P., Knox, R., Powell, J., Water, C., Marshall, J. Oates, M and Stone, P., (2011), 'Stratigraphy of the Anthropocene', Philosophical Transactions of the Royal Society A 369:1938 : 1036-55.

Žižek, S., (2011), Living in the End Times, London: Verso:

Note

\footnotetext{
${ }^{1}$ See for example Crutzen's (2006) consideration of geoengineering proposals not only with regard to anthropogenic greenhouse gas emissions, but also in relation to the role played by atmospheric aerosols in contributing to 'global dimming’.
} 